\title{
Anaesthetic Management of a Child with Congenital Rubella Syndrome Posted for Cochlear Implant - A Case Report
}

\author{
Rohini Sagadevan $^{1}$, R Arun Kumar ${ }^{2}$, K Pazhanambigai ${ }^{3}$ \\ ${ }^{1,3}$ Senior Resident, Department of Anaesthesiology, PSG Institute of Medical Sciences and Research, \\ Coimbatore, Tamilnadu, India \\ ${ }^{2}$ Associate Professor, Department of Anaesthesiology, PSG Institute of Medical Sciences and Research, \\ Coimbatore, Tamilnadu, India
}

Corresponding Author: R Arun Kumar

\begin{abstract}
Congenital Rubella Syndrome (CRS) is a constellation of multi-system abnormalities and each problem has significant anaesthetic implications. These patients pose various challenges to anesthesiologists like unanticipated difficult airway, uncorrected cardiac lesions, etc. Anesthetic for cochlear implant in child with CRS has not been reported. Anaesthetic management in an infant with PS should be based on decrease in pulmonary vascular resistance (PVR), avoidance of tachycardia with sinus rhythm, myocardial depression, systemic hypotension and adequate intra vascular volume. Here we report the anaesthetic management of a 5 year aged child with congenital rubella syndrome - post device closure of Patent ductus arteriosus, bilateral cataract surgery with moderate branch pulmonary artery stenosis and mental retardation posted for cochlear implant.
\end{abstract}

Key words: Congenital rubella syndrome, pulmonary artery stenosis, difficult airway, cochlear implant, patent ductus arteriosus.

\section{INTRODUCTION}

Congenital Rubella Syndrome (CRS) develops in an infant as a result of maternal infection with Rubella virus during first trimester and subsequent fetal infection. The main abnormalities are sensorineural deafness, cardiac defects, eye defects, brain damage, thrombocytopenia, hepatosplenomegaly and neonatal jaundice. The cardiac defects are Patent Ductus
Arteriosus (PDA), septal defects and stenosis of pulmonary artery and its branches. The brain damage includes microcephaly and mental retardation. Other manifestations are growth retardation, anemia, type 1 diabetes, lymphadenopathy, metaphyseal 'celery staking' changes in long bones and dermal erythropoiesis 1 .

The child usually requires cardiac surgery before performing non cardiac surgery. We are presenting a case of 5 year girl child with congenital rubella syndrome in whom cardiac procedure and cataract surgery was performed in childhood and now posted for cochlear implant.

\section{CASE REPORT}

A 5 year old female child with a known case of CRS weighing $11 \mathrm{~kg}$ with sensorineural deafness was posted for cochlear implant. She was born by term caesarean section with birth weight of 1.9 $\mathrm{kg}$. The child had bilateral congenital cataract, a developmental delay and was suspected to have congenital rubella syndrome. 2D ECHO done during first month of life showed moderate sized PDA, moderate valvular pulmonary stenosis (pressure gradient - 35mmHg) with small ostium secundum atrial septal defect. Follow up ECHO at 3 months showed PDA, mild pulmonary stenosis (pressure gradient $20 \mathrm{~mm} \mathrm{Hg}$ ) and significant coarctation of aorta. Patient underwent PDA device 
closure at 8months of age and cataract surgery at one year of age.

During preanaesthetic checkup child was found to be hyperactive, mentally retarded, unable to speak and delayed milestones. Cardiac evaluation revealed pansystolic murmur (grade 3) on auscultation. ECHO done prior to surgery revealed device closure of PDA, bilateral mild to moderate branch pulmonary artery stenosis (pressure gradient $28 \mathrm{mmHg}$ ). Chest $\mathrm{X}$ - ray showed mild cardiomegaly. Baseline investigations were normal. She was taken up for surgery under American society of anaesthesiologist Grade 2 with informed high risk consent and explained 8 hours starvation for solids and clear fluids up to 2 hours prior to surgery.

Anaesthesia was planned with general anesthesia controlled ventilation and invasive arterial line. Fasting guidelines were confirmed. Intravenous (IV) access was obtained before surgery in the ward. Infective endocarditis prophylaxis was give according to American Heart Association (AHA) 2007 guidelines as the turbulent flow caused by severe pulmonary stenosis has increased affinity for development of endocarditis. In the operating room defibrillator, emergency cardiac medication and difficult airway cart were kept ready. IV line patency was checked and connected to ringer lactate with $1 \%$ Dextrose. Child was premedicated with Injection Glycopyrolate $0.1 \mathrm{mg}$ IV and Injection Pentazocine 6mg IV under Electrocardiogram (ECG) and pulse oximetry monitoring in preoperative room.

Continuous monitoring of ECG, noninvasive blood pressure and oxygen saturation was done and recorded. Child was pre-oxygenated with $100 \%$ oxygen with $6 \mathrm{~L}$ flow in Jackson Rees circuit. Child was induced with Injection Thiopentone $75 \mathrm{mg}$ IV smoothly. Bag mask ventilation done and Inj.Vecuronium 1mg IV given. Anaesthesia was deepened with oxygen in air and Sevoflurane (2-4\%) and meticulous Smooth intubation was done in 3 minutes following Vecuronium administration with 4.5 sized cuffed endotracheal tube to prevent stress response. Right Radial artery cannulation was done using $22 \mathrm{G}$ venflon and transduced. Anaesthesia was maintained with oxygen:air (60:40), Sevoflurane 2-3\% and Inj.Vecuronium.

Inj.Dexmeditomidine $10 \mathrm{mcg}$ IV bolus was given. Intraoperative hemodynamics were closely observed and maintained. Hypertension and tachycardia was treated with Injection Esmolol 1mg boluses. Hypotension was managed with Inj. Phenylepherine $5 \mathrm{mcg}$ boluses.

Analgesia was supplemented with Injection Paracetamol 160 mg IV. Adequate hydration was ensured. Intraoperative period was uneventful and child was extubated post procedure after adequate reversal from neuromuscular blockade using Injection Glycopyrolate $0.1 \mathrm{mg}$ IV and Injection Neostigmine $0.5 \mathrm{mg}$ IV. Patient was shifted to postoperative ward for observation and postoperative period was uneventful. Child was discharged on $3^{\text {rd }}$ postoperative day.

\section{DISCUSSION}

Rubella virus also termed as German Measles involves multisystem abnormalities and each pose a significant anaesthetic challenge. CRS is a contagious disease spreading through droplets mode of transmission which is developed in an infant as a result of maternal infection with Rubella virus during first trimester and subsequent fetal infection ${ }^{2}$. The classical triad for CRS are sensorineural deafness, cardiac defects and eye defects. The major concerns of unanticipated airway abnormalities, uncorrected cardiac valvular or shunt pathology and low birth weight presenting with manifestations of failure to thrive pose a serious threat in anaesthetizing a CRS child ${ }^{3}$.

Wells et al showed various upper airway anomalies like subglottic stenosis, shortened trachea, and short glottis carinal length associated with many congenital syndromes ${ }^{4}$. Low birth weight of the child have increased sensitivity to the opioids, barbiturates and anaesthetic inhalation 
agents due to immature development of blood brain barrier and decreased ability of the drugs to get metabolized ${ }^{5}$. Hypotension, hypothermia and hypoglycaemia are also reported in low birth weight child with CRS. Eye abnormalities include retinopathy, cataract, glaucoma and microphthalmia ${ }^{6}$. Incidence of cardiac defects in CRS with eye involvement is as high as $95 \%$ and commonest is $\mathrm{PDA}^{5}$. These children seek surgical intervention for cleft lip/cleft palate repair, cataract extraction, congenital cardiac septal defect correction like PDA, atrial septal defect, severe pulmonary stenosis manifesting as severe pulmonary hypertension ${ }^{7}$ and for hearing loss. Uncorrected congenital disease with manifestations of severe pulmonary stenosis poses a major threat and a challenge to an anaesthesiologist in a CRS child $^{3}$. Anaesthetic management in a child with PS should be based on avoidance of systemic hypotension, maintenance of sinus rhythm and an adequate intra vascular volume, with awareness of the potential for myocardial ischaemia ${ }^{8,9}$.

$$
\text { Central nervous system }
$$

manifestations include brain damage manifesting as mental retardation, microcephaly and meningoencephalitis ${ }^{10}$. Other features include hepatosplenomegaly, neonatal jaundice, growth retardation, transient haemolytic anaemia, transient pneumonitis, dermal erythropoiesis (blueberry muffin syndrome), inguinal hernia, undescended testis and thrombocytopenia $^{11}$. Our child underwent cardiac procedure at 8 months of age - PDA device closure and bilateral cataract surgery at 1 year of age.

The anaesthetic goals during noncardiac surgeries are to maintain a normal systemic vascular resistance (SVR) and pulmonary vascular resistance (PVR) ratio $^{12}$. Factors like hypoxia, hypercarbia, hypothermia and acidosis which lead to increased PVR should be avoided ${ }^{13}$. Heart rate should be maintained in normal or slightly higher levels. Defibrillator, emergency cardiac drugs and difficult airway cart has to be kept ready. IE prophylaxis is necessary as the pulmonary stenosis produce a turbulent flow and increases the chance for infective endocarditis.

The child was adequately premedicated to prevent separation anxiety leading to tachycardia and hypertension. IV induction was done with Inj.Thiopentone to avoid haemodynamic instability. Deeper plane of anesthesia was maintained before intubation to avoid intubation stress response. Invasive monitoring was done for early recognition of haemodynamic instability and prompt management. Nitrous Oxide and high dose opioids were avoided as it would increase $\mathrm{PVR}^{14}$. Low tidal volume without positive end-expiratory pressure was used for controlled ventilation to maintain PVR. Adequate depth of anaesthesia was maintained throughout the procedure. IV fluids were carefully titrated to avoid cardiac overload. There was an episode of hypotension which was managed by titrated doses of Phenylephrine, hypertension and tachycardia with titrated doses of Esmolol. Adequate analgesia was given with Paracetamol and Dexmeditomidine and child was extubated post procedure after adequate reversal.

Haemodynamic instability should be anticipated and should be prepared to manage the same. In our child perioperative period was uneventful and child was pain free in postoperative room with stable hemodynamics.

\section{CONCLUSION}

Congenital Rubella Syndrome involves multisystem abnormalities with each posing unique anaesthetic problem. A proper understanding of cardiac problems in CRS and thorough knowledge regarding their anaesthetic implications enables successful outcome in managing these cases. Multidisciplinary approach in a tertiary unit in managing such cases is always a challenging task. 


\section{REFERENCES}

1. Divekar DS, Galande MV, Shidhaye RV. Anaesthetic challenges for congenital rubella syndrome. Anestesia Pediatrica e Neonatale, 2012, 10(2).

2. Namaei MH, Ziaee M, Naseh N. Congenital rubella syndrome in infants of women vaccinated during or just before pregnancy with measles-rubella vaccine. Indian J Med Res2008; 127: 551-554.

3. Robertson SE, Featherstone DA, GacicDobo M, Hersh BS. (2003). Rubella and congenital rubella syndrome: global update .Pan Am J Public Health, 14(5).

4. Kulkarni K, Deshpande S, Namazi I. (2009). Anaesthetic Management of a Child with Multiple Congenital Anomalies Scheduled for Cataract Extraction. Indian J Anaesth, 53(6), 683-87.

5. Williams A, George PE, Dua V. (2012 JanJun). Anesthetic considerations in a preterm Extremely low birth weight neonate posted for exploratory laparotomy. Anesth Essays Res, 6(1), 81-83.

6. Givens KT, Lee DA, Jones T, Ilstrup DM. Congenital rubella syndrome: ophthalmic manifestations and associated systemic disorders. Br J Ophthalmol. 1993, 77, 358363.

7. Moore JW and Mullins CE. Severe subaortic stenosis associated with congenital rubella syndrome: Palliation by percutaneous transcatheter device occlusion of a patent ductus arteriosus. Pediatric Cardiology 1986; 7(4):221-223.
8. Naitam MJ, Tirpude GN. Anaesthetic Management of a Child with Congenital Rubella Syndrome. Research Chronicle in Health Sciences 2016,2(4),283-285

9. Jackson JM, Thomas SJ. Valvular heart disease. In: Kaplan JA, ed. Cardiac Anaesthesia. Pliladelphia: WB Saunders Company 1993, 629680.

10. George IO, Frank-Briggs AI, Oruamabo RS. Congenital rubella syndrome: pattern and presentation in a southern Nigerian tertiary hospital. World J Pediatr 2009, 5, 287-291.

11. Menghraj SJ. (2012 Sep-Oct). Anaesthetic considerations in children with congenital heart disease undergoing non-cardiac surgery. Indian J Anaesth, 56(5), 491-95.

12. Stuckey D. Congenital heart defects following maternal rubella during pregnancy. Brit Heart J.1956; 18:519.

13. Pallavi Gaur et al. Unique anaesthesia problems encountered in congenital rubella syndrome. International Journal of Advances In Case Reports, 2015;2(11):686688.

14. Morice A, Ulloa-Gutierrez R, Avila-Augero ML. Congenital rubella syndrome: progress and future challenges. Expert Rev Vaccines 2009, 8, 323-331.

How to cite this article: Sagadevan R, Kumar RA, Pazhanambigai K. Anaesthetic management of a child with congenital rubella syndrome posted for cochlear implant - a case report. Gal Int J Health Sci Res. 2021; 6(1): 34-37. 